\section{LA CONSTRUCCIÓN DISCURSIVA DE LA DIFERENCIA SEXO-GENÉRICA EN LA VII CONFERENCIA IBEROAMERICANA DE MINISTROS DE JUVENTUD}

Páginas $15-34$

\author{
THE DISCOURSE CONSTRUCTION OF THE SEX-GENDER DIFFERENCE IN \\ THE 7TH IBEROAMERICAN CONFERENCE OF MINISTERS OF YOUTH ${ }^{1}$
}

\section{Lorena Natalia Plesnicar ${ }^{2}$}

Palabras clave: Juventud, género, embarazo, sexualidad, deserción escolar.

Keywords: Youth, gender, pregnancy, sexuality, school desertion.

\section{Resumen}

El artículo presenta algunos avances del proyecto de tesis doctoral en curso denominado "La construcción discursiva del conocimiento sobre la juventud y su educación en documentos de redes y organismos relacionados con América Latina (1980-2000)" que se desarrolla en el marco del Programa de Doctorado en Ciencias Sociales de Flacso, Argentina. Específicamente, el artículo analiza cómo se construye discursivamente el embarazo adolescente como problema en la VII Conferencia que Organización Iberoamericana de la Juventud emitió en el año 1994. Para el estudio del documento recurrimos al Análisis Crítico del Discurso (ACD). Lo resultados del análisis muestran que la intersección de los tópicos edad-joven-mujer permite la construcción del embarazo en la adolescencia como problemático. Lo que el documento pone en cuestión es la sexualidad adelantada o anticipada en la juventud y, a partir de esto, se incluyen temas como el aborto, el SIDA y la deserción escolar.

\begin{abstract}
The paper presents some advances of the doctoral thesis project "The Discourse Construction of the Knowledge about Youth and Education in the Documents of Networks and Organizations related to Latin America (19802000)." This is developed within the framework of the Doctorate Program on Social Science by Flacso, Argentina. Particularly, this paper analyzes how the adolescent pregnancy concept is discursively constructed as a problem in the $7^{\text {th }}$ Conference that the Latin American Youth Organization held in 1994. To
\end{abstract}

1 Traducción de Inés Gabriela Guerrero Revisión Centro de Traducción del Instituto de Idiomas UAM.

2 Profesora en Nivel Inicial (UNLPam). Profesora de Ciencias de la Educación (UNLPam). Máster en Dirección y Gestión de Centros Educativos (Universidad de Barcelona). Doctoranda en Ciencias Sociales (FLACSO-Argentina). Docente de la Universidad Nacional de La Pampa. Becaria Doctoral del Consejo Nacional de Investigaciones Científicas y Técnicas.

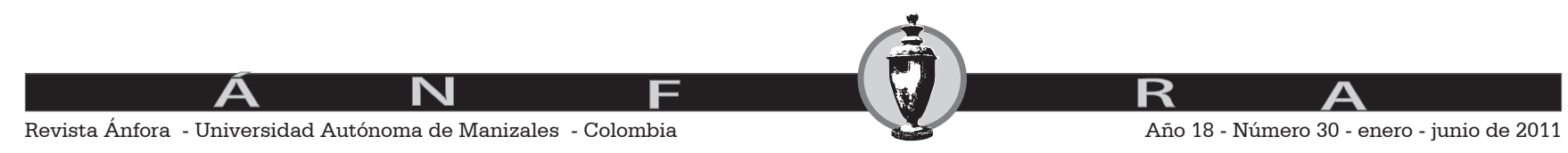


do this, the analysis was done through the Critical Discourse Analysis. The results show that the intersection of topics such as age, youth, womanhood allows the construction of adolescence pregnancy as a problem. This paper mainly focuses on early or anticipated sexuality in youth and, based on them, topics such as abortion, AIDS and school desertion are analyzed.

\section{Presentación}

Desde hace décadas, existe amplio consenso entre los investigadores sociales en la adopción de una concepción constructivista de la ciencia - y también de sus resultados y conocimientos - que supone que los hechos científicos son construcciones, implican el trabajo artesanal práctico mediante el cual se elaboran, transforman, defienden o rechazan distintas representaciones, concepciones, inscripciones, narrativas, según la perspectiva teórica que se desee adoptar (Callon y Latour 1991; Latour y Woolgar 1979).

En el marco de estos supuestos, aceptamos que la construcción del conocimiento en general y, del disciplinario en particular, tiene una historia que se da en el marco de determinadas constricciones sociales, culturales y políticas, entre otras. En el caso de los estudios de juventud, esto puede advertirse, de forma más o menos evidente, si se establece una comparación entre su propio desarrollo histórico y el de las Ciencias Sociales.

En un artículo de los últimos años, el antropólogo Carles Feixa (2006), propone un recorrido por la historia del siglo XX a partir de la descripción de las teorías sobre la juventud - en términos de generaciones ${ }^{3}$ - . Como el autor mismo reconoce en la Conclusión, su perspectiva es sesgada, ya que la revisión se inscribe en una cierta versión de los hechos, es decir, una mirada de corte occidental — con énfasis en lo europeo y Estadounidense- . Pese a esto, Feixa asume el desafío de recuperar algunos aportes a dicha historia que son originales de América Latina. En este sentido, Feixa describe para el primer tercio del siglo XX una fase ensayística-especulativa, una empírico-modernizadora para las décadas de 1960 y 1970 y, por último, una etapa que se inicia a mediados de los 1980 caracterizada por una mirada etnográfico experimental ${ }^{4}$.

Para el siglo XXI, Feixa delimita tres temas que los investigadores latinoamericanos deberían incluir en sus agendas: "en primer lugar, la construcción histórica y cultural de la juventud a partir de la diversidad; en segundo lugar, la relectura de las teorías sobre las generaciones en una lógica latinoamericana; y en tercer lugar, la metamorfosis de la juventud en la era de la globalización" (2006, pp. 43).

En nuestra perspectiva, si bien esta propuesta avanza en la delimitación de temas no estudiados —o escasamente abordados- obvia, al mismo tiempo, otros vacíos, otras ausencias que en el cruce de distintas disciplinas hemos detectado en el marco de nuestra investigación. En este
3 Feixa distingue las siguientes generaciones: Generación A (Adolescente), Generación B (Boy Scout), Generación K (Komsomol), Generación S (Swing), Generación E (Escéptica), Generación R (Rock`n'roll), Generación H (Hippy), Generación P (Punk), Generación T (Tribu) y Generación R (Red).

4 En la etapa ensayística, sitúa los escritos de J. E. Rodó, $\mathrm{J}$. Ingenieros, J. Vasconcelos y J. C. Mariátegui. En los años 1930 destaca los aportes desde la psicología de A. Ponce. En la década de los sesenta y setenta, Feixa cita las investigaciones de G. Medina Echavarría, M. Matterlart, A. Solari, A. Gurrieri, E. Torres-Rivas y E. Faletto. La lista de investigadores se amplía en el último período: J. MartínBarbero, I. Agurto, M. Canales, J. M. Valenzuela, M. Margulis, J. Padilla, H. J. Cubides, M. Laverde, C. E. Valderrama, G. Medina, R. Reguillo, M. Marín, G. Muñoz y A. Caccia-Bava. Si bien Feixa no cita el trabajo de Cecilia Braslavsky Estudios e investigaciones sobre juventud en América Latina: balance y perspectivas como fuente, es ése el documento donde la autora delineo dichas etapas y las desarrolló con mayor con profundidad conceptual.

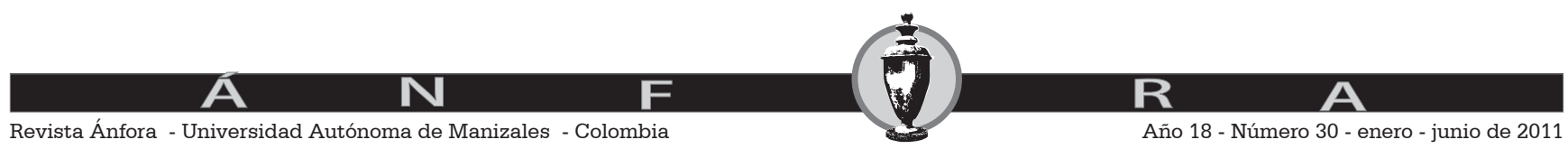


sentido, nos interesa recuperar otros andamiajes teóricos, otras apuestas metodológicas que desde las Ciencias Sociales, pueden sumar nuevas herramientas disponibles a los estudios sobre la juventud. En efecto, por una parte, optamos por el Análisis Crítico del Discurso (ACD) como apuesta metodológica de creciente interés entre los investigadores. Por otra parte, la recuperación de los estudios de mujeres ${ }^{5}$, las teorías feministas ${ }^{6}$ y del género augura una línea de trabajo de creciente interés.

En el marco de esta delimitación, el artículo presenta los avances de la tesis doctoral en curso denominada "La construcción discursiva del conocimiento sobre la juventud y su educación en documentos de redes y organismos relacionados con América Latina (1980-2000)" que se desarrolla en el Programa de Doctorado en Ciencias Sociales de Flacso, Argentina. El corpus documental está conformado por las Conferencias Iberoamericanas de la Juventud que la Organización Iberoamericana de la Juventud (OIJ) emitió durante el período $1980-2000 .^{7}$

El propósito de este escrito es analizar la construcción discursiva de la diferencia sexo-genérica y, para ello, se optó por el análisis de la VII Conferencia Iberoamericana de Ministros de Juventud que data del año 1994 porque en ella encontramos numerosas referencias sobre construcciones de género. A partir de la selección de algunos fragmentos significativos del documento vamos a desarrollar el siguiente argumento: el objeto juventud se define a partir de una clasificación en términos de edad y, desde ella, se presentan ciertas construcciones de género. Dentro de la categoría juventud se incluye el sintagma "mujeres jóvenes" que, de manera implícita, se corresponde con el de "varones jóvenes" y actualiza de este modo la clasificación biologicista de los dos sexos. A través de distintos mecanismos discursivos a las "mujeres jóvenes" se les asigna el clásico esencialismo atribuido a las mujeres que plantea el ser femenino como sinónimo de ser madre. En este punto, la intersección de los tópicos edad-joven-mujer conducen a la definición de una problemática: el embarazo adolescente. En el marco de esta construcción se sitúa otro hecho cuestionado: el aborto. Para finalizar el trabajo, se plantean algunos comentarios sobre el SIDA y la deserción escolar en tanto consecuencias de una sexualidad supuestamente adelantada o anticipada.

\section{La construcción discursiva de la diferencia sexo-genérico en la VII Conferencia de la OIJ}

Como anticipamos, nos proponemos describir y analizar la construcción discursiva del sistema sexo-género en la VII Conferencia de la OIJ. La expresión "sistema de sexo-género" la recuperamos del trabajo ampliamente difundido de Gayle Rubin llamado El tráfico de mujeres: notas sobre la "economía política" del sexo que data del año 1975 y que se convertido en un referente teórico obligado para los/las estudiosos/as del género.
5 Para una revisión de los alcances de estos estudios, véase Stimpson (1998).

6 Optamos por el uso del término "feminismos" en plural, dado que no es nuestro propósito examinar las diferencias entre los llamados feminismos posmoderno, multicultural, posestructuralista, transnacional, postcolonial, por mencionar los más difundidos en la literatura disponible de los últimos años.

7 Hasta la fechas se han realizado las siguientes Conferencias: Madrid (1987), Buenos Aires (1988), San José (1989), Quito (1990), Santiago de Chile (1991), Sevilla (1992), Punta del Este (1994), Buenos Aires (1996), Lisboa (1998), Panamá (2000), Salamanca (2002), Guadalajara (2004), La Habana (2006) y Chile (2009). Desde una perspectiva histórica, la continuidad de las Conferencias dio lugar, entre otros acontecimientos, a la creación de la Organización Iberoamericana de la Juventud (OIJ) que, como un organismo internacional de carácter multigubernamental, se constituyó en septiembre de 1992 en coincidencia con la celebración de la VI Conferencia de Ministros Iberoamericanos de Juventud. En dicha ocasión se acordó iniciar un proceso de institucionalización de este foro de diálogo, concertación y cooperación en materia de juventud. El Presidente de dicha Conferencia, suscribió un Acuerdo de Cooperación con el Secretario General de la Organización de Estados Iberoamericanos para la Educación, la Ciencia y la Cultura (O.E.I.) y, en ese hecho se crea la O.I.J. en calidad de organismo internacional asociado al anterior pero dotado de plena autonomía orgánica, funcional y financiera. Dos años más tarde, durante la realización de la VII Conferencia Iberoamericana de Ministros de Juventud, en Punta del Este se aprobaron los Estatutos de la

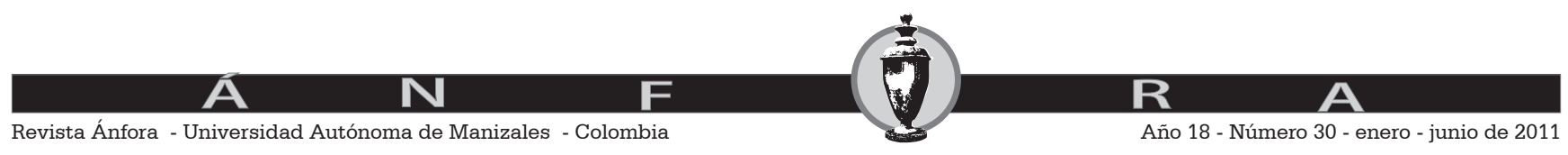


En dicho trabajo, Rubin plantea el análisis de las causas de la opresión de las mujeres y, para ello, acude principalmente a los aportes de Claude LéviStrauss, Frederick Engels, Sigmund Freud y Jacques Lacan. Con el propósito de describir la organización social de la sexualidad - y la reproducción de las convenciones de sexo y género que conlleva- Rubin diferencia los sintagmas "modo de reproducción" y "patriarcado" y, finalmente, opta por el término "sistema sexo-género" en el que la opresión se explica como un producto de las relaciones sociales. Para Rubin "toda sociedad tiene un sistema, de sexo-género - un conjunto de disposiciones por el cual la materia prima biológica del sexo y la procreación humanas son conformadas por la intervención humana y social y satisfechas en forma convencional, por extrañas que sean algunas de las convenciones" (1996, pp. 44). Y, para observar estos sistemas de sexo-género la autora describe los sistemas de parentesco que se constituyen en el eje de su argumentación. ${ }^{8}$

Si bien esta línea de abordaje se convirtió en un punto inicial de numerosas investigaciones no por ello quedó exenta de cuestionamientos ${ }^{9}$. Tal vez la más importante fue la que la misma Rubin esgrimió en un trabajo sobre la estratificación sexual, los conflictos sexuales, la opresión sexual, entre otros, publicado en el año 1989. Allí revisó en forma crítica el sintagma "sistema sexo-género" dado que su primera formulación trasmitía, en cierta forma, el sexo como realidad natural y, en consecuencia, constante y universal. Ante este esencialismo sexual la autora propone una teoría radical del sexo basada en la tesis central de que la sexualidad es un producto humano y que el sexo es político. En esta línea Rubien afirma que: "En contraste con las opiniones que expresé en "The Traffic in Women", afirmo ahora que es absolutamente esencial analizar separadamente género y sexualidad si se desean reflejar con mayor fidelidad sus existencias sociales distintas. Esto se opone a gran parte del pensamiento feminista actual, que trata la sexualidad como simple derivación del género" (1986, pp. 54). En todo caso, si bien es importante incluir estas revisiones que la misma Rubin desarrolló, ellas no impugnan de forma total su concepto de "sistema sexo-género" esbozado en la década anterior.

Para abordar la formación del objeto juventud, proponemos tres niveles de análisis del texto: enunciativo, temático y argumentativo. Dado que en este artículo, el eje gira principalmente en torno del análisis de género, recuperamos dichos niveles pero con el propósito de profundizar el análisis desde esa clave.

En consecuencia, desde el nivel enunciativo, surgen como interrogantes principales ¿de qué modo se nombra a los y las jóvenes? ¿Qué rasgos y características se le atribuyen? ¿Cómo puede explicarse la aparición de determinados enunciados y no de otros? Desde el temático, preguntamos ¿cuáles son los temas relacionados con la juventud más frecuentes en el documento? ¿Cuáles son las omisiones, los vacíos, los silencios? Por último, desde el nivel argumentativo ¿por medio de qué argumentos tratan a los y las jóvenes? ¿Se articulan éstos? ¿A través de qué estrategias discursivas?
O.I.J. que establecen sus normas de funcionamiento. En 1996, en Buenos Aires se suscribió el documento que crea formalmente la Organización Iberoamericana de Juventud. Actualmente la OIJ reúne a representantes de los siguientes países: Argentina, Bolivia, Brasil, Chile, Colombia, Costa Rica, Cuba, Ecuador, El Salvador, España, Guatemala, Honduras, México, Nicaragua, Panamá, Paraguay, Perú, Portugal, República Dominicana, Uruguay y Venezuela (Plesnicar, 2009).

8 Es importante señalar, por otra parte, la definición de género que Rubin arguye: "el género es una división de los sexos socialmente impuesta. Es un producto de las relaciones sociales de sexualidad. Los sistemas de parentesco se basan en el matrimonio; por lo tanto, transforman a machos y hembras en 'hombres' y 'mujeres', cada uno una mitad incompleta que sólo puede sentirse entera cuando se une con la otra. Desde luego, los hombres y las mujeres son diferentes" (las comillas pertenecen al original) (1996, pp. 58-59).

9 Las principales críticas provienen de las corrientes feministas postmodernas que cuestionan los dualismos de naturaleza-cultura, sexo-género y cuerpo-mente presentes en distintos marcos teóricos de las teorías del género. En palabras de Stimpson: "la teoría posmoderna nos pone en guardia contra el pensamiento de oposiciones binarias, contra el hábito de dividir un mundo complicado en la dualidad polarizada de 'sexo' y 'género', equivalente a 'naturaleza' y 'cultura'" (las comillas pertenecen al original) (1998, pp. 136).

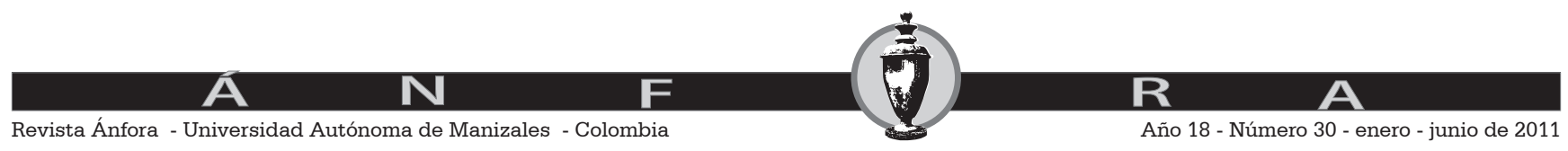


Respecto a las formas enunciativas que aparecen en el documento es importante destacar la relevancia que adquiere la perspectiva generacional en las formas enunciativas ya que en forma recurrente aparecen expresiones tales como: nuevas generaciones de iberoamericanos, las nuevas generaciones de nuestros países. También pueden distinguirse dos grupos o conjunto de expresiones. El primero se refiere a los modos generales de nombrar, y así aparecen expresiones tales como la juventud, los jóvenes, la juventud de nuestros países, sectores de jóvenes, nuestros jóvenes, población joven y los jóvenes de cada uno de nuestros países. El segundo grupo reúne nominaciones que vinculan juventud con criterios territoriales. Por último, se citan en menor número sintagmas tales como "las jóvenes" y "mujeres jóvenes"

En el primer grupo, la referencia sobre los jóvenes podría interpretarse como alusiva al joven en tanto sujeto masculino, invisibilizando de esta manera a las jóvenes mujeres. Por otra parte, en el uso del pronombre "la" (la juventud) puede advertirse que su pretensión de unidad, de homogeneidad, oculta también las posibles diferencias en las condiciones sociales, políticas, económicas, entre otras, que caracterizan a los habitantes de los países que participan en la conferencia. Un análisis de esta supuesta homogeneidad está presente en la entrevista realizada a Pierre Bourdieu (1990), "La 'juventud' no es más que una palabra", que data de 1978. En ella, Bourdieu propuso nombrar a las juventudes distinguiendo en ese momento los jóvenes que trabajaban de los adolescentes que eran estudiantes ${ }^{10}$.

Desde una perspectiva similar, Cecilia Braslavsky (1986a), en un trabajo pionero sobre la producción de conocimientos sobre la juventud en América Latina y el Caribe, analiza los estudios realizados desde 1983 y allí reconoce que: "Precisamente uno de los aportes del conjunto de estudios e investigaciones sobre el tema consisten en haber desmitificado definitivamente la idea de la existencia de 'una' juventud en América Latina. La juventud de cada país es muy diferente a la de los demás, y al interior de cada nación los estilos de inserción y las modalidades de acción de los jóvenes varían notablemente" (las comillas pertenecen al original) (1989, pp. 32).

En otro grupo de enunciaciones sobre juventud se advierte que el nombramiento aparece en relación con la configuración del espacio desde diferentes criterios territoriales. En este sentido, pueden diferenciarse dos tendencias. La primera, relaciona juventud con Iberoamérica y aparece en expresiones tales como: "la juventud iberoamericana" y "nuevas generaciones de Iberoamericanos". La segunda, relaciona juventud con América Latina y así encontramos como ejemplo "jóvenes latinoamericanos".

Como ya hemos dicho, los documentos utilizan distintos vocablos para nombrar la juventud, pero entendemos, en términos generales, que los sintagmas "mujeres jóvenes" y "los jóvenes" son los que nos posicionan frente a un discurso en el que se instala la regulación binaria de la sexualidad y, al mismo tiempo, contribuye a suprimir la inteligibilidad de otras identidades de género posible (Ciriza, 2004). ${ }^{11}$
10 Esta identificación de la juventud con los estudiantes también está presente en los escritos de Walter Benjamin, a modo de ejemplo puede citarse el texto "La vida de los estudiantes" que fue publicado en la revista Der Neue Merkur en 1915.

11 Según Alejandra Ciriza, "La regulación binaria de la sexualidad suprimiría la multiplicidad subversiva sometiendo los procesos de constitución de sujetos a las reglas de la heterosexualidad obligatoria y a las pautas del sexo normalizado y reproductivo regulado por el discurso médico y jurídico" (Ciriza 2004, pp. 2).

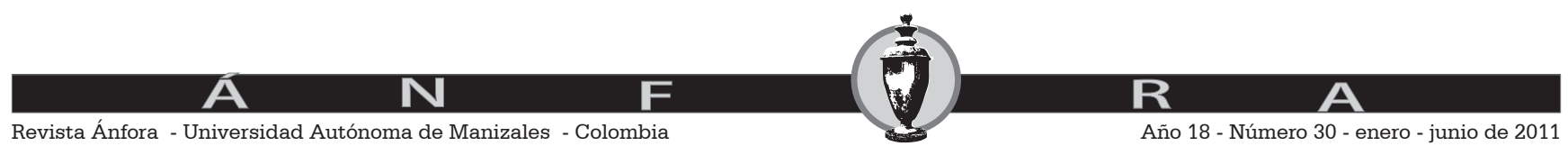


Como anunciamos en la Presentación nuestro argumento es que el objeto juventud se construye a partir de una clasificación en términos de edad y, es a partir de esto, que se presentan ciertas construcciones de género. Pasemos entonces a describir esta línea.

\section{La edad como eje de definición de la juventud}

La edad, en tanto dimensión sociodemográfica, ha generado distintas formulaciones respecto de la definición de grupos etarios y, así contribuye a generar un ordenamiento de la sociedad en grupos, sectores, etapas (Dávila León 2004). Para las ciencias de la conducta, la categoría edad adquiere un rol principal en la descripción de las etapas del desarrollo (niñez, adolescencia, juventud, adultez, vejez) en las cuales los individuos que se ubican en la misma etapa comparten determinadas características asignadas a ellas (cambios biológicos, comportamientos, capacidades). En los últimos años, este tipo de argumentos han sido ampliamente discutidos dado su carácter esencialista y, esto ha dado lugar a pensar la edad social de los individuos (Gutiérrez y Ríos, 2006). ${ }^{12}$

Desde otra perspectiva, en el caso de las indagaciones teóricas de Carles Feixa (1996), él propone situar sus aportes en la antropología del ciclo vital y de las relaciones intergeneracionales como marco de análisis global. En su revisión histórica sobre la antropología de la juventud y la antropología de la vejez, concluye en la necesidad de evitar la tendencia de aislar los estudios sobre la edad de otras dimensiones culturales y, por ello, propone combinar dos perspectivas analíticas: la construcción social de las edades y la construcción generacional de la cultura. ${ }^{13}$

En nuestro análisis, nos interesa en particular recuperar sus reflexiones vinculadas con la primera perspectiva. Veamos algunos de los interrogantes que Feixa sitúa en ella: "¿Cómo ha cambiado históricamente la organización del ciclo vital? ¿Cómo se organizan hoy las fronteras y los tránsitos entre las diversas etapas biográficas? ¿Cuáles son las transformaciones recientes en las condiciones sociales de las distintas edades? ¿Cómo influyen las instituciones en la vida de los grupos de edad subalternos?" (1996, pp. 16).

Estas preguntas, trasladadas a nuestro propio abordaje investigativo, nos permiten problematizar algunos de los mecanismos discursivos que operan en los documentos y, que traducen los modos en que se configuran los grupos de la sociedad. Asimismo, nos acercan a indagar sobre el uso socialmente dado a la edad como factor definitorio de la categoría juventud. Un ejemplo:

En el año 2000 alrededor de 100 millones de habitantes de América Latina serán personas menores de 25 años y el
12 Una definición sobre "edad social" puede consultarse en el Diccionario Crítico de Ciencias Sociales en la entrada Generaciones/Clases de edad de Enrique Martín Criado.

$13 \mathrm{El}$ autor explica estas perspectivas del siguiente modo: "La construcción cultural de las edades. Se trata de estudiar las formas mediante las cuales cada sociedad estructura las fases del ciclo vital, delimitando las condiciones sociales de los miembros de cada grupo de edad (es decir, el sistema de derechos y deberes de cada persona según su grado de edad), así como las imágenes culturales a las que están asociados (es decir, el sistema de representaciones, estereotipos y valores que legitiman y modelan el capital cultural de cada generación). La edad aparece como un constructo modelado por la cultura, cuyas formas y contenidos son cambiantes en el espacio, en el tiempo y en la estructura social" (1996, pp. 15). "La construcción generacional de la cultura. Se trata de estudiar las formas mediante las cuales cada grupo de edad participa en los procesos de creación y circulación cultural, lo que puede traducirse en determinadas percepciones del espacio y del tiempo, en formas de comunicación verbal y corporal, en mecanismos de resistencia y cohesión social, en producciones estéticas, lúdicas y musicales, en discursos simbólicos e ideológicos, y en apropiaciones sincréticas de los flujos transmitidos por las grandes agencias culturales. La cultura aparece como un constructo modelado por las relaciones generacionales, cuyos agentes filtran y remiten constantemente los mensajes culturales" (1996, pp. 16).

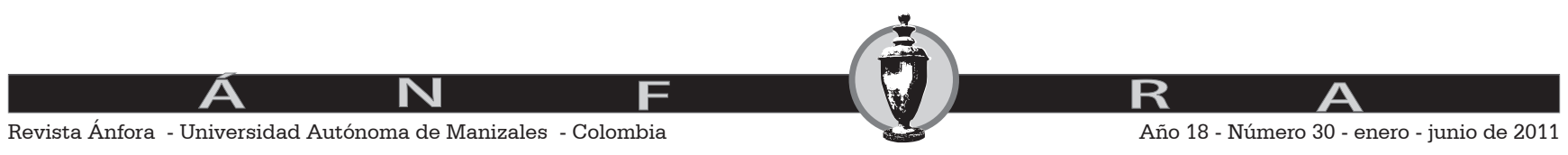


previsible incremento de estas cifras tiende a predecir la agudización de enormes problemas sociales relacionados con la marginalidad y la exclusión social que afectarán a grandes contingentes de jóvenes latinoamericanos (VII Conferencia, 1994, pp. 2).

La cita nos sitúa ante una definición de juventud: "personas menores de 25 años" y, de este modo, remite a ciertos aquellos abordajes teóricos que explican la juventud en términos de enclasamientos etarios. En general, se enmarcan aquí los aportes que provienen del campo de la psicología, más allá de la escuelas que pueden distinguirse en él (Moreno y del Barrio, 2000).

Para algunos autores, la naturalización de la periodización del ciclo vital en etapas responde a la injerencia de dos agentes en el campo de la edad: uno, el mercado y, el otro, el desarrollo de las ciencias humanas en general y, de la psicología evolutiva, en particular (Gutiérrez y Ríos, 2006). En nuestra perspectiva asumimos que no sólo el mercado junto las instituciones que producen el conocimiento científico son quienes participan en la construcción de este tipo de abordaje sino que también es muy importante el papel de algunos organismos internacionales que contribuyen a difundir y estandarizar este tipo clasificación para operar sobre lo social.

Esta afirmación se sustenta básicamente en los argumentos de Pierre Bourdieu quien explica el carácter arbitrario de las divisiones entre las edades. Para él, "en la división lógica entre jóvenes y viejos está la cuestión del poder, de la división (en el sentido de repartición) de los poderes. Las clasificaciones por edad (y también por sexo, o, claro, por clase...) vienen a ser siempre una forma de imponer límites, de producir en orden en el cual cada quien debe mantenerse, donde cada quien debe ocupar su lugar (las cursivas pertenecen al original) (1990, pp.164). En efecto, consideramos que esta producción del orden social va más allá de las academias y del mercado y que necesita de otros mecanismos y dispositivos que legitimen e instituyan los sentidos y funciones sociales de la edad a efectos de hacerlos regulables con fines políticos.

Retomemos el fragmento de la Conferencia. Si bien no podemos detenernos en la asociación entre juventud- problemas sociales- marginalidad- exclusión social, aquí sí es importante resalar que la expresión "grandes contingentes de jóvenes latinoamericanos" no sólo remite al dato estadístico del inicio de párrafo (100 millones) sino que también expresa cómo opera discursivamente la estrategia de homogeneizar un grupo (el de los y las jóvenes) mediante esencialismos etarios (menores de 25 años) que, a su vez, con el uso del término "contingentes" auscultan otras referencias ineludibles. Como también ya hemos señalado, "jóvenes latinoamericanos" remite a construcciones geopolíticas de recurrente presencia en las Conferencias del corpus que estudiamos.

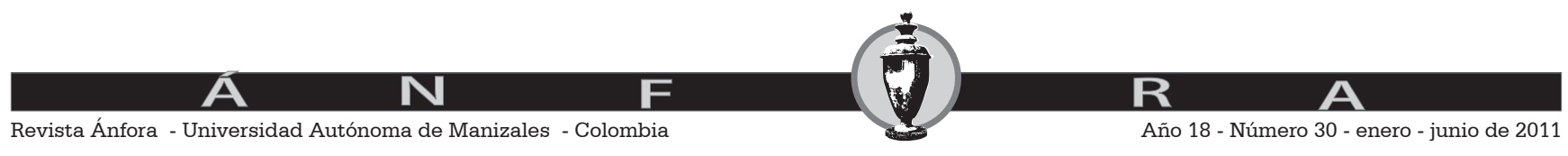


A modo de síntesis provisoria sobre la edad en tanto parámetro en las definiciones de juventud, podemos decir que, aunque la categoría etaria no es suficiente para estudiar lo adolescente y juvenil, numerosos investigadores acuerdan en su necesidad para precisar algunas delimitaciones iniciales y básicas (Dávila León, 2004).

Hasta aquí observamos cierto determinismo etario para la definición del objeto juventud. A continuación, describiremos cómo dicha construcción posibilita la definición del embarazo en la adolescencia como problemático.

\section{La construcción discursiva del embarazo adolescente como problema}

Dentro de la categoría juventud se incluye el sintagma "mujeres jóvenes" que, de manera implícita, se corresponde con el de "varones jóvenes" y actualiza así la clasificación de los dos sexos biológicos. A través de distintos mecanismos discursivos a las "mujeres jóvenes" se les asigna el clásico esencialismo atribuido a las mujeres que, plantea el ser femenino como sinónimo de ser madre. En este punto, la intersección de los tópicos edad-joven-mujer conducen a la definición de una problemática: el embarazo adolescente. En efecto, esto se advierte principalmente con la introducción del sintagmas tales como: "embarazos precoces" y "maternidad precoz".

Desde la propuesta teórica que adoptamos, Michel Foucault afirma que el análisis de los discursos debe contemplar cuatro nociones: la del acontecimiento, la de la serie, la de la regularidad y la de la condición de posibilidad. En su encuadre, la cuarta regla, sobre la exterioridad ofrece pistas significativas para nuestro trabajo. Según este autor, "no ir desde el discurso hacia su núcleo interior y oculto, hacia el corazón de un pensamiento o de una significación que se manifestarían en él; sino, a partir del discurso mismo, de su aparición y de su regularidad, ir hacia sus condiciones externas de posibilidad, hacia lo que da motivo a la serie aleatoria de esos acontecimientos y que fija los límites" (1973, pp. 53).

En efecto, es importante indagar algunas de las condiciones sociales, políticas e históricas que posibilitaron la emergencia de las preocupaciones sobre la sexualidad de la juventud - y los temas asociados con ella- en los discursos internacionales. En esta línea, un hecho que cobra relevancia es el surgimiento de las investigaciones sobre fecundidad y embarazo adolescente —con sus orientaciones biomédicas o sociales- que en América Latina y el Caribe datan de la década de los 1980. Algunas autoras, entre ellas Edith Alejandra Pantelides (2003), sostiene que entre los motivos principales del surgimiento de estas investigaciones se destaca las altas tasas de fecundidad de menores de 20 años que se registraban en las estadísticas de la época ${ }^{14}$.
14 Otro hecho que colabora como dato de las afirmaciones anteriores es la realización de la Conferencia sobre Fecundidad en Adolescentes en América Latina y el Caribe en el año 1989 convocada por The Population Council y The Pathfinder Fund que se constituyó en el primer foro de discusión sobre el tema.

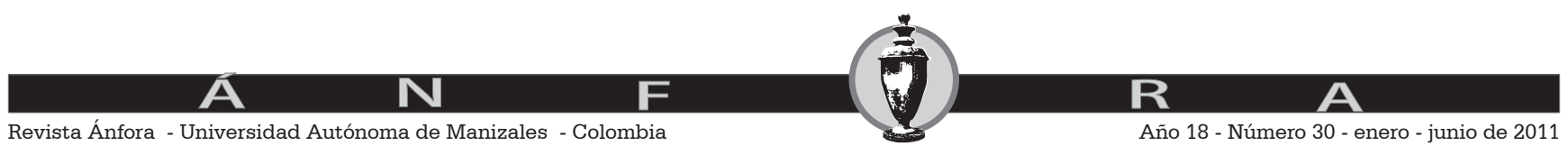


Ya hemos dicho que los firmantes de la Conferencia, en el marco de una clásica concepción reproductivista de los sexos, construyen la maternidad en la adolescencia como problemática. A la definición de mujer joven se le adjudica la nota de la identidad femenina propia de las sociedades patriarcales: la correspondencia entre mujer y madre (Guy, 1998). De esta manera, se establece un prototipo identitario: mujer es ser madre, pero al trasladarlo a las jóvenes se torna algo del orden de lo disruptivo y, de ahí, la insistencia de la maternidad en la adolescencia como problemática. Veamos un ejemplo:

No menos preocupante es la situación de las mujeres jóvenes en la Región, cuya problemática adquiere personalidad propia. Un antecedente descriptivo de dicha situación es el indicador de maternidad que señala que el 14,5\% de los nacimientos que se producen en América Latina, corresponden a madres menores de 20 años (VII Conferencia, 1994, pp. 3).

En este punto, nos parece importante recurrir a algunas de las reflexiones sobre el lugar de las mujeres en la historia que es un tema con amplia presencia en la literatura sobre los estudios de las mujeres, los feministas y los de género y pueden aportarnos algunas orientaciones para profundizar el análisis.

Mirta Henault señaló que el ingreso de las mujeres al mundo del trabajo en la moderna sociedad industrial estuvo condicionado "para cumplir el rol al que las condena su sexo" (1973, pp. 19). En efecto, la inferioridad en el orden público, la debilidad social y la subordinación son las notas principales que en la inserción pública reactualizan la situación de las mujeres en sus hogares. En cierta forma, esta concepción sobre la debilidad de las mujeres -y, jóvenes, además- está presente en el fragmento antes citado cuando se afirma que "la situación de la mujeres jóvenes en la Región, cuya problemática adquiere personalidad propia".

La situación de las mujeres jóvenes es definida como "problemática" y, esta relación se establece con la maternidad. Aquí es posible diferenciar algunas líneas de análisis. Por un lado, presentar la maternidad como un "problema" sólo de mujeres, reactualiza en cierta forma, las discusiones sobre la sexualidad, los derechos reproductivos y otros temas de la agenda feminista de larga data (Ávila, 2000). En este sentido, pareciera que la expresión "personalidad propia" reafirma esto, es decir, lo define como un problema en sí mismo desvinculado de otras dimensiones que podrán implicarse en su descripción.

Por otrolado, como ha sidoampliamentereseñado, eldiscursoubica alas mujeres en su papelexclusivo de la reproduccióny, esto implica, parafraseandoa Virginia Vargas (2003), asumir individualmente los costos sociales de la maternidad ${ }^{15}$. Esto supone, asimismo, la designación de atributos de género establecidos estáticamente en forma binaria, de forma exclusiva y como un destino prescripto. En efecto, se actualizan los argumentos que sostienen la complementariedad de los sexos y el paradigma heteronormativo de la vida sexual ${ }^{16}$.
15 María Betânia Ávila cita a Marilena Chauí para explicar que: "La permanencia de la ideología naturalizadora es nítida en el caso de las mujeres, cuyo cuerpo es invocado como determinación natural. Es posible notar que el cuerpo femenino parece ser un elemento natural e irreductible, haciendo que la mujer permanezca esencialmente ligada al plano biológico (de la procreación) (...) el cuerpo femenino recibe un conjunto de atributos derivados de su atributo más inmediato: la maternidad" (2000, pp. 67). En línea con esto, Ávila afirma que la construcción de la naturaleza femenina es producto de los discursos disciplinadores de los hombres que han sido introyectados por las mujeres.

16 Algunas investigadoras como Judith Butler se han ocupado de cuestionar estas afirmaciones, así ella afirma: "La hipótesis de un sistema binario de géneros sostiene de manera implícita la idea de una relación mimética entre género y sexo, en la cual el género refleja al sexo o, de lo contrario, está limitado por él. Cuando la condición construida del género se teoriza como algo completamente independiente del sexo, el género mismo pasa a ser un artificio ambiguo" (2007, pp. 54-55).

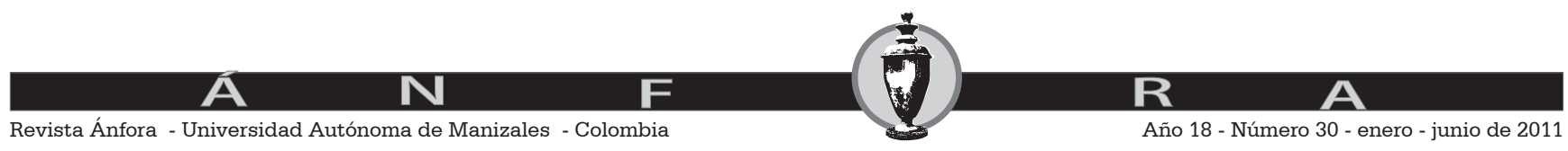


Otra de las notas a destacar del fragmento citado es la ausencia de una interpelación en términos de clase, es decir, que la experiencia de la maternidad en la juventud - como en otras etapas o períodos de la vida- puede experimentarse de maneras diferentes según la clase social (Ciriza, 1997). Sólo por mencionar una línea argumentativa sobre esto, Mario Margulis (1996, 2009) en sus trabajos del campo de la sociología de la juventud, resalta que mientras para las clases bajas ser mujer se correlaciona con ser madre, para las clases altas, para ser madre, primero hay que ser mujer — y esto implica algunos logros vinculados con las trayectorias académicas, las posibilidades de inserción laboral, entre otros-. Desde otra perspectiva, Eleonor Faur (2003) arguye que las mujeres de los grupos más desventajados portan imágenes de género tradicionales en las cuales la maternidad es altamente valorada y, esto es consecuencia de las imposibilidades de desarrollo en otras áreas de sus vidas y del desconocimiento y uso de los métodos anticonceptivos.

Párrafos anteriores, decíamos que el embarazo en la adolescencia se define como problemático. Si continuamos la indagación sobre este supuesto advertimos que esto se vincula con cierta determinación o concepción del tiempo. En el siguiente fragmento, los firmantes avanzan sobre la descripción de los problemas asociados con las mujeres jóvenes:

El contexto sociocultural que viven las mujeres jóvenes determina un conjunto de condiciones desfavorables que les afecta de modo especial. Las madres adolescentes tienen más riesgos que aquellas mayores de 20 años y los embarazos precoces muestran una tendencia a crecer. (VII Conferencia, 1994, pp. 3)

En la frase "Las madres adolescentes tienen más riesgos que aquellas mayores de 20 años" se utiliza, de nuevo, la clave de la edad. Sin embargo, a diferencia de la definición analizada en otro fragmento ya citado (personas menores de 25 años) aquí las madres adolescentes son las menores de 20 años. Desde el nivel argumentativo, la afirmación contundente "tienen más riesgos" funciona casi como victimización de las jóvenes pero omite mencionar a qué tipo de riesgos están expuestas las mujeres-jóvenes-madres.

Por otra parte, la inclusión del sintagma "embarazos precoces" remite, como dijimos, a una determinada concepción del tiempo y, en consecuencia, de la asociación entre tiempo y ciclo vital —o etapas de la vida, según la perspectiva teórica que se adopte-—. ${ }^{17}$

En el marco de las ideas que expusimos, un embarazo precoz supone que éste no se da en una edad propicia, aparece como un hecho anticipado, como si fuera algo antes de lo debido, concepción que podríamos vincular con ciertos prejuicios adulto-céntricos que ya han sido ampliamente reseñados en
17 El uso del término precoz, sea tanto para calificar los embarazos como la maternidad, es común en los estudios sociodemográficos de los 1990. Sólo por citar un libro que ha tenido amplia difusión puede mencionarse La maternidad precoz. La fecundidad adolescente en la Argentina de E. A. Pantelides que fue editado por UNICEF.

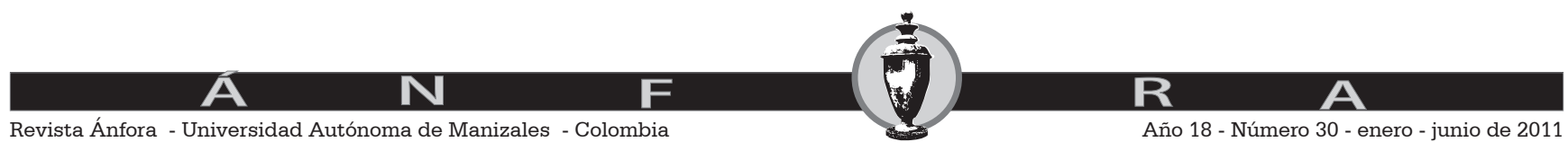


las investigaciones sobre juventud. Una rápida revisión del término "precoz" en el diccionario permite apoyar nuestra afirmación anterior. Temprano, prematuro, que aparece antes de lo habitual, son algunas de las palabras que se utilizan para explican el vocablo.

Sin embargo, lo que queda sin explicitar en la Conferencia es sobre qué lógicas se define la organización del tiempo, en otras palabras, a qué edad un embarazo sería, por oposición, no-precoz. En este punto, suponemos que el término precoz proviene de las investigaciones socio-demográficas de la fecundidad adolescente en las que los especialistas utilizan con frecuencia el par "fecundidad precoz" y "fecundidad tardía" para explicar el concepto de "fecundidad total".

En todo caso, lo que el discurso muestra es cómo a través de cierta cronologización de la vida se define la maternidad y, a partir de ella, se plantea de modo implícito los mecanismos sociales de regulación de los cuerpos. Por lo dicho, la articulación edad- juventud (mujer joven) —embarazo precoz permite que los firmantes construyan la maternidad en la adolescencia como problemática. A continuación, presentamos algunas observaciones sobre la inclusión del aborto en el discurso de la VII Conferencia.

\section{El aborto: ¿y la soberanía sobre el propio cuerpo?}

En la literatura disponible sobre las teorías feministas y los estudios de mujeres producida en América Latina, existe amplio consenso en aceptar que la inequidad entre los géneros es una nota común e histórica en los diversos sectores y clases sociales (Henault, 1973). También es cierto que las demandas y los reclamos de los grupos de mujeres, feministas y activistas no han sido homogéneas, cambiaron de acuerdo con los contextos políticos, sociales, económicos y culturales en los que estos colectivos despliegan sus estrategias (Ciriza, 2004, 1997).

En la Argentina, desde hace unas décadas, las luchas de las mujeres por los derechos civiles y políticos ha sido ampliamente investigada. En los últimos años, el tema de los derechos sexuales y reproductivos ocupa un lugar de sumo interés en la agenda de los/as cientistas sociales que se sienten atraídas/os por la perspectiva de género como fuente promisoria en la investigación social.

Es importante señalar, sin embargo, que estas discusiones e intereses investigativos - como otros - se construyen en el marco de las constricciones políticas, ideológicas, culturales de un contexto epocal. En este sentido, un ejemplo notable es la discusión sobre la legalidad del aborto - como un derecho de determinación sobre el propio cuerpo- que se inscribe en la agenda de reclamos de ciertos movimientos de mujeres y feministas. Para Dora Barrancos, "Es imperioso que las mujeres sean auxiliadas en la decisión libre

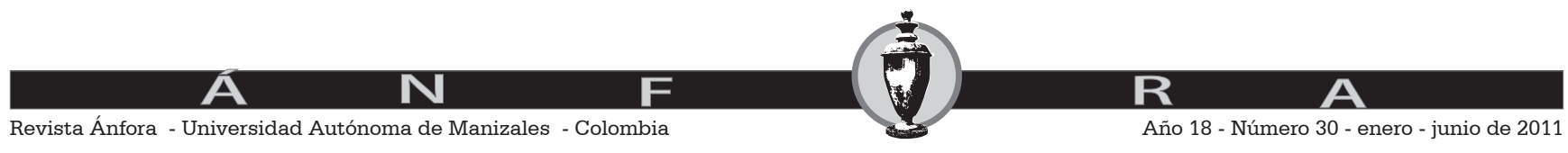


de procrear o de no hacerlo, y es una obligación del Estado de derecho garantizar la individuación y la autonomía. Las mujeres deben gozar del derecho pleno a la soberanía sobre sus cuerpos, y la penalización del aborto se encuentra entre los resabios más oscuros del imperativo de sometimiento a un destino inexorable. Se trata justamente de la vida y de su disfrute digno. Seguir adelante con un embarazo no deseado es pronosticar insatisfacción, inadecuación del maternaje y secuelas psíquicas en el ser que no ha sido querido" (2008, pp. 188-189).

Esta querella no es reciente desata un sinnúmero de polémicas que se inscriben en posiciones ideológicas, religiosas y políticas muchas veces contradictorias ${ }^{18}$. Desde una perspectiva histórica, tal como lo explica Alejandra Vasallo (2005) el aborto legal y gratuito realizado en hospitales públicos formó parte del programa de once puntos que el Frente de Lucha por la Mujer (FLM) elaboró en el año 1975 en ocasión de la declaración de las Naciones Unidas del Año Internacional de la Mujer. Este dato demuestra, en forma contundente, cómo el tema, aunque presente desde hace décadas, no ha logrado generar consensos que modifiquen las prácticas sociales y algunos de los estereotipos asociados con ellas. En la Conferencia el tema aparece expresado de la siguiente manera:

El aborto, la mayoría de las veces realizado sin medidas profilácticas adecuadas y en situaciones de clandestinidad, desata un proceso de mortalidad que alcanza un $30 \%$ en mujeres menores de 24 años (VII Conferencia, 1994, pp. 3).

De nuevo, aparece la edad como un rasgo para clasificar los grupos de la sociedad. Así, la expresión la "mujeres menores de 24 años" puede equipararse a "mujeres jóvenes". Es decir, las mujeres jóvenes son las mujeres menores de 24 años. Lo que el texto no dice o invisibiliza es cómo se construye ese criterio demarcatorio.

Por otra parte, es importante señalar la mención de un porcentaje de mortalidad (30 \%) que, como no se citan otros datos informativos referidos al resto de los grupos etarios, el lector —o los lectores- no puede(n) establecer comparación alguna. Es decir, si no se tienen otras estadísticas sobre las distintas cohortes de mujeres, el dato mencionado en sí mismo no ofrece ninguna posibilidad de puesta en diálogo con otras informaciones relevantes para hacer afirmaciones bien fundamentadas respecto de los alcances del aborto en las mujeres jóvenes. Asimismo, habría que considerar las especificidades de las naciones que conforman la región latinoamericana.

Aunque pareciera que el párrafo denuncia las prácticas de aborto y su relación estrecha con la pobreza al decir que "la mayoría de las veces realizado sin medidas profilácticas adecuadas y en situaciones de clandestinidad", el texto no deja en claro una posición política al respecto.
18 Sin dudas, la oposición al debate sobre los derechos reproductivos más difundido entre el feminismo y algunos movimientos de mujeres de América Latina es el que se estableció con la Iglesia Católica (Ávila, 2000).

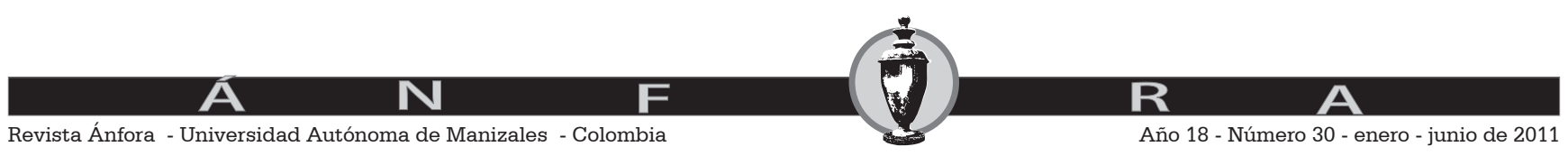


Esto expresa, en cierto sentido, el clima de época, es decir, lo que se puede decir o no en un momento histórico, las luchas que operan en él, los discursos dominantes, entre otros aspectos. Cabe recordar, que años antes de la emisión de la Conferencia que aquí analizamos, en el $V$ Encuentro Feminista Latinoamericano y del Caribe realizado en San Bernardo (desde el 18 al 24 de noviembre de 1990) se acordó declarar el día 28 de septiembre como Día por el Derecho al Aborto de las Mujeres de América Latina y del Caribe. La elección de la fecha tuvo el propósito de recordar la declaración de libertad de vientres para los/as hijos/as de las esclavas, sancionada en 1888 en Brasil.

Asimismo puede afirmarse que en materia de legislación internacional, la década de los años 1990 dio lugar a ciertos cambios en el reconocimiento de los derechos de las mujeres. A modo de ejemplo, pueden citarse las declaraciones de tres Conferencias: en 1993, la Conferencia Mundial de Derechos Humanos que tuvo lugar en Viena; en 1994, la Conferencia Mundial de Población y Desarrollo celebrada en El Cairo y; en 1995, la Conferencia Mundial sobre la Mujer realizada en Beijing.

De la misma época datan otros instrumentos internacionales como la Convención Interamericana para Prevenir, Sancionar y Erradicar la Violencia contra la Mujer (1994), el Estatuto de la Corte Penal Internacional (1998) y la Convención para la Eliminación de Todas las Formas de Discriminación en contra de la Mujer (CEDAW) (1999) que exponen, en cierta medida, la relevancia de los temas sobre las mujeres en la agenda internacional. ${ }^{19}$

Los acuerdos que emanan de los documentos y encuentros anteriores, sin dudas, han otorgado reconocimiento a los derechos reproductivos pero, sin embargo, no han impactado en forma similar en las legislaciones nacionales sobre el aborto (Guillaume y Lerner, 2007). En este sentido, una línea a profundizar en el futuro es el estudio de las situaciones de institucionalización del aborto en los distintos países representados en la OIJ.

\section{Consecuencias de una sexualidad anticipada: el SIDA y la deserción escolar}

Numerosos autores acuerdan, en el marco de los estudios antropológicos y sociológicos, que el cuerpo es un producto social y cultural. Es esta afirmación la que sustenta una serie de indagaciones sobre las prácticas sociales de regulación, control y dominación de los cuerpos. En este escenario, y desde una lógica enraizada en la biología, las mujeres por su capacidad reproductiva se han constituido en un punto de referencia para esgrimir sobre sus cuerpos distintas estrategias de control. Lo que lleva implícitos, sin dudas, otros mecanismos de dominación ideológica inspirados en la jerarquía de los sexos biológicos. En el marco de estos supuestos, el discurso médico no sólo se erige como principal referente de regulación de los cuerpos sino que, por su propia legitimidad frente a otros discursos —el religioso, por ejemplo_, se consolida como un argumento de autoridad por
19 En el caso de la Argentina, este último tratado junto con la Convención Internacional de los Derechos de Niños y Adolescentes fueron incorporados en el cuerpo de la Constitución Nacional a partir de la reforma del 1994 (Gutiérrez, 2003).

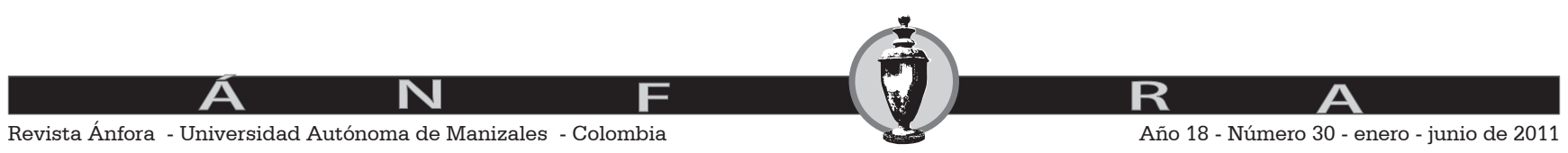


su aceptado estatuto de cientificidad.

A continuación, describimos la asociación entre sexualidad y salud presente en el documento de la VII Conferencia. Aquí es importante señalar que los firmantes retoman el discurso médico de la época y, de este modo, se refieren a ciertos temas que son prioritarios en sus agendas e intervenciones. Un fragmento muy significativo al respecto asegura:

Un dato extremadamente preocupante es el referido a la incidencia del SIDA en el mundo que señala, según datos de la Organización Mundial de la Salud (O.M.S), que la mitad de los enfermos y portadores es menor de 25 años (VII Conferencia, 1994, pp. 3).

En primer lugar, puede decirse que la expresión "la mitad de los enfermos y portadores es menor de 25 años" alude a que la mitad pertenece al grupo de la juventud. Esto se dice porque, como señalamos antes, en el mismo documento la juventud se define como personas menores de 25 años.

Por otra parte, el fragmento apela a la técnica argumentativa de la autoridad ampliamente utilizada en los discursos políticos. Esta estrategia consiste en mencionar una persona o una institución reconocida, con autoridad, prestigio o fama, para apoyar un punto de vista expresado en el discurso (Van Dijk, 2004). En este caso específico, se recurre al nombre de la Organización Mundial de la Salud y, a sus estadísticas, como fuente de conocimiento válido o autorizado.

Desde otra clave de lectura, puede advertirse la asociación que opera entre juventud y enfermedades, que en este caso remite el tema a la sexualidad - de la juventud-por referirse a una de las enfermedades venéreas que ha captado el mayor interés de la medicina en las últimas décadas.

José Antonio Díaz Rojo asegura que la terminología médica, en tanto discurso científico, posee una carga cultural ya que está impregnada de las concepciones que imperan en una sociedad. Para este autor, los vocablos referidos a las enfermedades conllevan una carga connotativa y, en este sentido, afirma: "La enfermedad no sólo es una realidad biológica, sino también un hecho social y cultural, lo que hace que se conciba y perciba a través de determinados estereotipos, que funcionan como imágenes o representaciones descriptivas y explicativas de contenido emotivo (de miedo, esperanza, idealización, utopía, distopia, etc.) y están cargadas de connotaciones y asociaciones ideológicas" (2005, pp. 79).

Cabe agregar, además, que todavía existen sectores religiosos y políticos que sostienen que el SIDA es algo así como "un castigo divino" y que es consecuencia de la ruptura con ciertas normas o leyes morales sobre el sexo. Esta concepción tiene consecuencias directas en los procesos de marginación y de estigmatización social
20 Hay un libro, muy interesante, llamado "La enfermedad y sus metáforas" y "El SIDA y sus metáforas" en el que la autora, Susan Sontag, desarrolla el argumento según el cual, la sociedad utiliza determinadas enfermedades para operar respecto de ciertos criterios de salud individual y colectiva. Al mismo tiempo, dichas metáforas funcionan para reforzar el orden social desde el que se originaron.

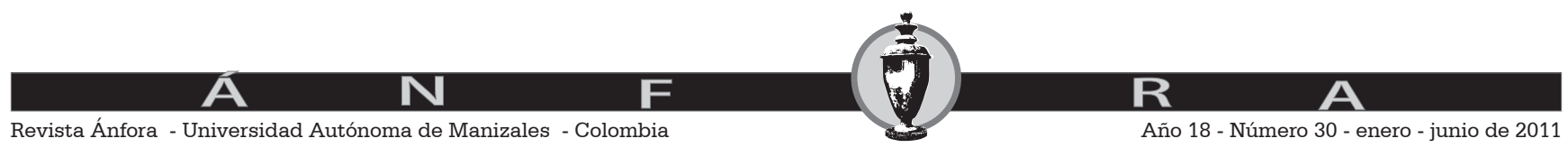


de quienes tienen la enfermedad. ${ }^{20}$

Asimismo, y como ya hemos señalado en el desarrollo de este artículo, los datos informativos que se presentan en la cita están escindidos de otros correspondientes al resto de los grupos o sectores de la sociedad. En todo caso, la estrategia discursiva de apelar al discurso médico —en tanto dotado de legitimidad social y cientificidad - intenta enfatizar lo problemático de una sexualidad anticipada y, por ello, se hace hincapié en el tema de las enfermedades. Es decir, que lo que el discurso pone en cuestión es la sexualidad de los y las jóvenes.

Esta misma referencia a la anticipación de la sexualidad aparece en el documento pero desde otra esfera de la vida de los sujetos: la educativa. En este sentido, es interesante cómo se articula maternidad precoz con deserción escolar. Citamos un ejemplo: "Las deserciones escolares a causa de una maternidad precoz marginan definitivamente a las Jóvenes de las oportunidades y de una inserción real en la sociedad" (VII Conferencia, 1994, pp. 3).

De forma similar a lo dicho antes no se advierte sobre qué parámetros se establece, en este caso, "la precocidad". El sintagma "maternidad precoz" viene a apoyar nuestra argumentación sobre la sexualidad anticipada, y en este caso, se sostiene sobre la construcción de la maternidad en la adolescencia como algo no deseable o problemático.

El fragmento se organiza desde un esquema causa-efecto. Causa: maternidad precoz, efecto: deserción escolar. La sentencia: "Marginan definitivamente a las Jóvenes de las oportunidades y de una inserción real en la sociedad" no sólo establece un determinismo (con el uso del adverbio de modo "definitivamente") enraizado en ciertos estereotipos de género, sino que omite las responsabilidades políticas y sociales que avalan dicha marginación. En otros términos, las asociaciones implícitas que establece la cita pueden sintetizarse en: joven—mujer—madre—marginación—deserción escolar.

La cita que presentamos, expone un ejemplo de cómo desde el discurso político se opera en el campo de la sexualidad de la juventud y en la regulación ideológica de las diferencias. De este modo, la maternidad precoz sólo se establece en relación con las mujeres jóvenes, y desvincula a los varones de la reproducción y las tareas asociadas con ella.

Lo señalado hasta aquí, hace suponer la interconexión de dos matrices discursivas cuyas fuentes abrevan en referentes disciplinares distintos. Por un lado, una concepción de juventud que deriva de una visión ligada a la psicología, y esto se advierte especialmente por el uso de la categoría adolescencia. Por el otro, la impronta del discurso sociológico, ya que aún reconociendo la posibilidad de maternidad en la adolescencia, esto se evalúa como precoz, es decir, se está afirmando la existencia de ciertas dificultades vinculadas con la marginalidad y con la inserción en la sociedad. Por ello, la maternidad adolescente es considerada como obstaculizadora de los proyectos de vida

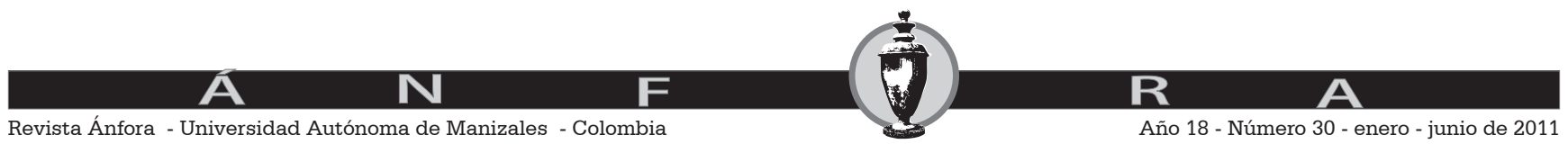


de las jóvenes, incluso de la posibilidad de concluir los estudios (y de ahí, la inclusión del problema de la deserción escolar). Estas ideas están presenten en investigaciones que datan de finales de los años 1980 en las que se argumentaba que la maternidad en la adolescencia podía explicarse como mecanismo de transmisión de la pobreza dado el menor nivel de educación que alcanzarían las jóvenes y con ello un menor estatus socioeconómico. Desde otra clave de lectura, se propuso un análisis inverso al anterior, es decir, se argumentó que la pobreza sería explicativa de las condiciones que conducen a los embarazos en la adolescencia (Pantelides, 2003).

En síntesis, las Conferencias, como otros discursos políticos, actúan como instancias que legitiman cierto imaginario de género y, en el caso de la importancia que asignan a la maternidad como explicativa de la deserción escolar, contribuyen a reforzar ciertas significaciones o estereotipos de género dominantes funcionales a prácticas discriminatorias.

\section{Conclusiones}

El análisis de la Conferencia desde una perspectiva que articula estudios de las mujeres, las teorías feministas y de género nos aproxima a ciertos discursos teóricos-históricos presentes en los países que conforman una región y al traspasar sus propios límites nos acercan a una perspectiva continental.

Los firmantes, desde una posición hegemónica discursiva, contribuyen a la difusión y creación (o re-creación) de representaciones, imaginarios, subjetividades e identidades en una coyuntura socio-histórica. Nuestro argumento central en este artículo, acerca de la construcción discursiva de la diferencia sexo-genérica en la Conferencia permite, desde un corpus documental no estudiado, explorar la ampliamente difundida tesis de las feministas sobre la variabilidad de los sistemas de género en distintos tiempos y lugares (Conway, Bourque y Scott, 1998).

El análisis realizado si bien puede decirse que recupera elementos teóricos bastante estudiados para el año de formulación del documento, tales como los embarazos en la adolescencia, la reducción de lo femenino a una esencialización de la capacidad biológica de reproducción, también incluye algunas asociaciones que son bastante interesantes si se contextualiza el lugar de los enunciadores. Es decir, en primer lugar hay una obvia clasificación biologicista de los sexos y, por ello, la distinción entre "mujeres jóvenes" y "varones jóvenes". En segundo lugar, la articulación de variables tales como edadjoven-mujer está en el origen de la configuración del embarazo adolescente como problemático. Es desde esta operación discursiva que se utilizan expresiones como "embarazos precoces" y "maternidad precoz" para designar a la sexualidad de "las" jóvenes como algo del orden de lo precoz, lo anticipado, lo inesperado.

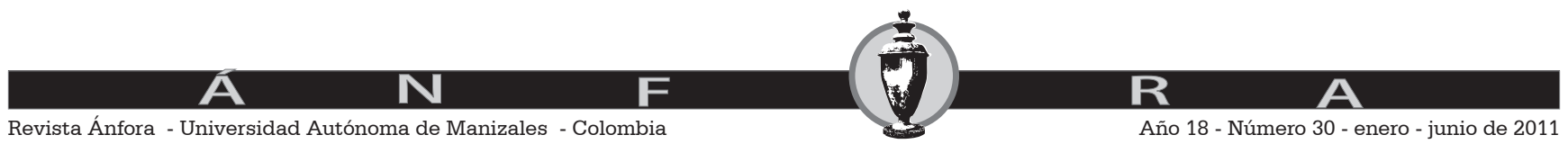


Lo que sí es sumamente sugestivo es la relación que se establece entre la sexualidad y sus consecuencias, es decir, la mención desde el nivel temático del SIDA y la deserción escolar como resultados más o menos aceptados o recurrentes. Tal vez esto está en relación directa con el origen del interés por la sexualidad de los/as jóvenes en las Ciencias Sociales. En un trabajo de los últimos años, Mónica Gogna, cita a Pantelides cuando afirma que dichas preocupaciones aparecen "a partir del interés por la fecundidad y, más tarde, se incrementa a raíz de la epidemia del sida. Es entonces, un interés 'secundario' o 'instrumental', surgido por inquietudes relativas no a la sexualidad en sí misma, sino a sus consecuencias" (las comillas pertenecen al original) (2005, pp. 34)

En síntesis, el análisis realizado se constituye en un aporte provocador si nos remitimos al género discursivo, es decir, las Conferencias como instrumentos de las políticas públicas con injerencias en distintos órdenes del escenario internacional que contienen elementos del paradigma patriarcal.

Un avance sustantivo sobre los temas que desarrollamos en este escrito sería poder introducir la pregunta sobre lo el texto invisibiliza, es decir, otras experiencias sociales radicalmente diferentes, otros mecanismos de constitución de las subjetividades alternativas a los mandatos hegemónicos de la heteronormatividad vigente. Esta lectura contribuiría a ofrecer un espacio de mayor inteligibilidad a los modos, por ejemplo, en que otras y otros jóvenes

21 Aquí es importante señalar que "no existe sólo la polaridad de dos géneros, femenino/masculino. Existen varios géneros o, mejor, actos performativos de género -esto es, formas del lenguaje que suelen repetirse hasta 'hacer un tipo de género'-, toda vez que las negociaciones de la sexualidad son diversas y dan lugar a múltiples adopciones de identidad, o de identificación, que sería riesgoso encasillar" (las comillas y cursivas pertenecen al original) (Barrancos 2008, pp. 18).

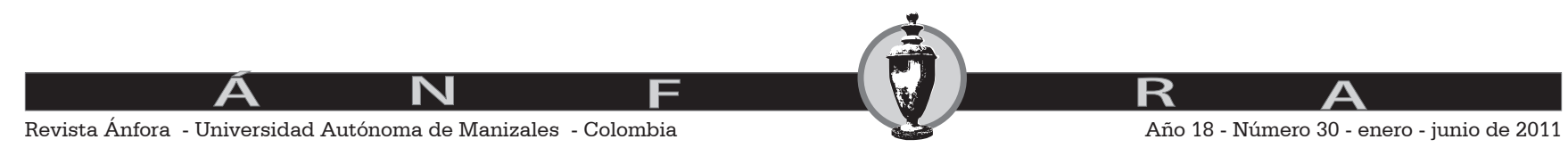


constituyen sus identidades de género en tensión con los designios de la sociedad patriarcal. ${ }^{21}$

\section{Bibliografía}

Ávila, M. B. (2000). Feminismo y ciudadanía: La producción de nuevos derechos. En Mujeres al timón: cuadernos para la incidencia política feminista (pp. 61-79). Lima: Flora Tristán, Agenda y Equidad de género.

Barrancos, D. (2008). Mujeres, entre la casa y la plaza. Buenos Aires: Sudamericana.

Bourdieu, P. (1990) La juventud no es más que una palabra. En P. Bourdieu. Sociedad y Cultura (pp. 163-171). México: Grijalbo.

Braslavsky, C. (1986) La juventud argentina: entre la herencia del pasado y la construcción del futuro. Revista de la CEPAL, 29, 41-55.

Butler, J. (1990/2007). El género en disputa. El feminismo y la subversión de la identidad. Barcelona: Paidós.

Callon, M. y Latour, B. (1991) La science telle qu'elle se fait. Anthologie de la sociologie des sciences en langue anglaise. Paris: La Découverte.

Ciriza, A. (2004). Notas sobre los límites de la importación teórica. A propósito de Judith Butler. El Rodaballo. Revista de política y cultura 15, 57-61.

(1997). Desafíos y perspectivas. Qué feminismo hoy. Cuyo, Anuario de Filosofía Argentina y Americana, 14, 153-168.

Conway, J. K., Bourque, S. C. y J. W Scott. (1998). El concepto de género. En M. Navarro y C. Stimpson (Comp.). ¿Qué son los estudios de mujeres? (pp. 167-178). Buenos Aires: Fondo de Cultura Económica.

Dávila León, O. (2004) Adolescencia y juventud: de las nociones a los abordajes. Ultima Década, 21, 83-104.

Díaz Rojo, J. A. (2005). Terminología médica y discurso social. En C. García de Toro y I. García Izquierdo (Eds.) Experiencias de Traducción. Reflexiones desde la práctica traductora (pp. 77- 92). Castellón de la Plana: Publicacion de la Universitat Jaume I.

Faur, E (2003/2008). ¿Escrito en el cuerpo? Género y derechos humanos en la adolescencia. En S. Checa (Comp.) Género, sexualidad y derechos reproductivos en la adolescencia (pp.37-75). Buenos Aires: Paidós.

Feixa, C. (2006). Generación XX. Teorías sobre la juventud en la era contemporánea. Revista Latinoamericana de Ciencias Sociales, Niñez y Juventud, 4, 2, 21-45.

(1996). Antropología de las edades. En J. Prat y A. Martínez (Eds)

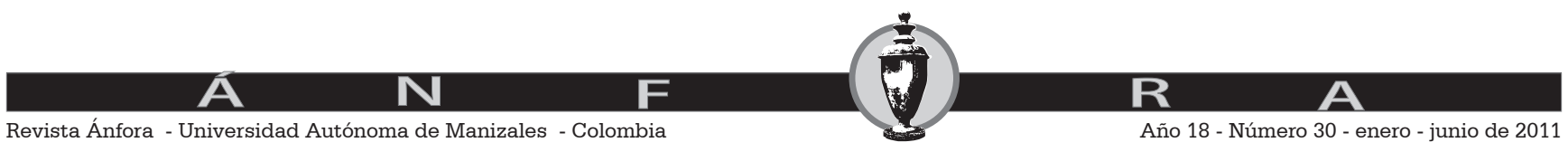


Ensayos de Antropología Cultural. Homenaje a Claudio Esteva-Fabregat (pp. 319-335). Barcelona: Ariel. http://cholonautas.edu.pe Acceso 21/01/10

Foucault, M. (1973/2005). El orden del discurso. Buenos Aires, Tusquets.

Gona, M. (2005). Estado del arte: investigaciones sobre sexualidad y derechos en la Argentina: 1990-2002. Buenos Aires: CEDES.

Guillaume, A. y Lerner, S. (2007). El aborto inducido en América Latina y el Caribe. Una revisión de la literatura de los años 1990 a 2005. ParísMéxico: CEPED.

www.ceped.org/cdrom/avortement_ameriquelatine_2007

Acceso

$20 / 02 / 10$

Gutiérrez, M. A. (2003/2008). Derechos sexuales y reproductivos de los adolescentes: una cuestión de ciudadanía. En S. Checa (Comp.) Género, sexualidad y derechos reproductivos en la adolescencia (pp.77-101). Buenos Aires: Paidós.

Gutiérrez, E. y Ríos, P. (2006). Envejecimiento y campo de la edad: elementos sobre la pertinencia del conocimiento gerontológico. Ultima Década, 25, 11-41.

Guy, D. (1998). Madres vivas y muertas. Los múltiples conceptos de la maternidad en Buenos Aires. En D. Balderston y D. Guy (Comp.) Sexo y sexualidades en América Latina (pp.231-256). Buenos Aires: Paidós.

Henault, M. (1973). La mujer y los cambios sociales. En M. Henault, P. Morton, P. y I. Larguía. Las mujeres dicen basta (pp.13- 40). Buenos Aires: Nueva Mujer.

Latour, B. y Woolgar, S. (1974/1985). La vida en el laboratorio. La construcción de los hechos científicos. Madrid: Alianza.

Martín Criado, E. Generaciones/Clases de edad. En R. Reyes (Dir.) Diccionario Crítico de Ciencias Sociales. http://umc.es Acceso 25/01/10

Moreno, A. y del Barrio, C. (2000). La experiencia adolescente. A la búsqueda de un lugar en el mundo. Buenos Aires: Aique.

Pantelides, E. A. (2003) Aspectos sociales del embarazo y la fecundidad adolescente en América latina. Trabajo presentado en el Seminario La fecundidad en América Latina: ¿transición o revolución? Organizado por el CELADE y el Centre de Recherche Populations et Sociétes, Université de Paris X-Nanterre, Santiago de Chile (Chile), 9-11 de junio. www.eclac. cl/publicaciones/xml/9/22069/lcg2229-p1.pdf Acceso 15/03/10

Plesnicar, L. N. (2009). El objeto juventud en la I Conferencia Iberoamericana de Juventud. Argentina. Revista Latinoamericana de Ciencias Sociales, Niñez y Juventud, 7, 2, 1209-1227. 
Rubin, G. (1996). El tráfico de mujeres: notas sobre la "economía política". En M. Lamas (Comp.) El género: la construcción cultural de la diferencia sexual (pp. 35-96). México: PUEG.

Rubin, G. (1989). Reflexionando sobre el sexo: notas para una teoría radical de la sexualidad. En C. Vance (Comp.). Placer y peligro. Explorando la sexualidad femenina (pp. 113-190). Madrid: Revolución. www.cholonautas.edu.pe Acceso 2/03/10

Sontang, S. (1996). La enfermedad y sus metáforas. El SIDA y sus metáforas. Madrid: Taurus.

Stimpson, C. (1998). ¿Qué estoy haciendo cuando hago estudio de mujeres en los años noventa? En M. Navarro y C. Stimpson (Comp.) ¿Qué son los estudios de mujeres? (pp. 127-165). Buenos Aires: Fondo de Cultura Económica.

Van Dijk, T. (2000/2004). La retórica belicista de un aliado menor. Implicaturas políticas y legitimación de la guerra de Irak por parte de José M. Aznar. Oralia, 7, 195-225.

Vargas, V. (2003). Los feminismos latinoamericanos y sus disputas por una globalización alternativa. En Mato, D. (Coord.). Políticas de identidades y diferencias sociales en tiempos de globalización (pp. 193-217).Caracas: FACES-UCV.

Vasallo, A. (2005). Las mujeres dicen basta: Feminismo y movilización política de los 70. En Andújar y otras. Historia, Género y política en los '70. Buenos Aires: Feminaria.

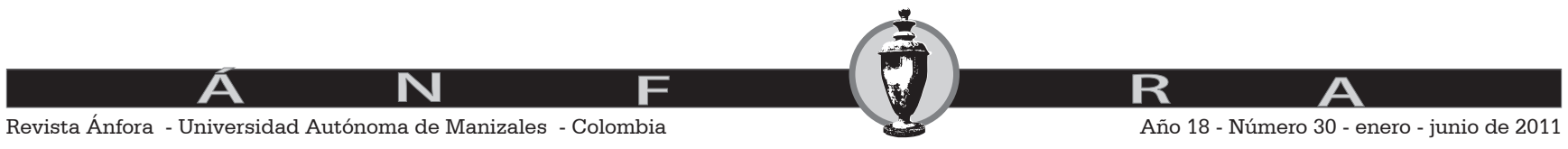

